\title{
A epistemologia de Imre Lakatos e sua (in)aplicabilidade à teoria econômica*
}

The epistemology of Imre Lakatos and its (in)applicability to economic theory

\author{
Tailiny Ventura e Lucas Casonato**
}

\begin{abstract}
Resumo: Este trabalho objetiva discutir a utilização da metodologia dos programas de pesquisa científica de Lakatos (MMPC) na teoria econômica. O artigo inicia com uma breve exposição da proposta lakatosiana. Em seguida são analisadas algumas aplicações da MPPC a diferentes abordagens econômicas, investigando como suas estruturas foram adequadas ao arcabouço de Lakatos. Na sequência são revistas algumas críticas a esse procedimento de adequação da proposta lakatosiana na economia. Nessa revisão é discutido o caráter social da ciência econômica, por requerer maior nível de subjetividade na investigação científica. É apontado que essa característica permite a coexistência de explicações teóricas alternativas para um mesmo fenômeno econômico. Com base nisso, conclui-se que o nível de subjetividade inerente à economia, enquanto ciência caracterizada por um lado social, torna mais difícil a aplicação da MPPC na teoria econômica.
\end{abstract}

Palavras-chave: Metodologia econômica; Imre Lakatos; Programas de pesquisa científica

\begin{abstract}
This paper aims to discuss the use of Lakatos's methodology of scientific research programs (MSRP) in economic theory. The article begins with a brief exposition of the Lakatosian proposal. Then, some applications of MSRP to different economic approaches are analyzed, investigating how their structures were adequate to the Lakatos framework. Following some criticisms of this process of the adequacy of the Lakatosian proposal in economics are reviewed. This review discusses the social character of economic science because it requires a higher level of subjectivity in scientific research. It is pointed out that this characteristic allows the coexistence of alternative theoretical explanations for the same economic phenomenon. Based on this, it is concluded that the level of subjectivity inherent in economics, as a science characterized by a social side, makes the application of MSRP more difficult in economic theory.
\end{abstract}

Keywords: Economic methodology; Imre Lakatos; Scientific Research Programs

JEL: B31; B41

\footnotetext{
* Submissão: 14/06/2019 | Aprovação: 25/04/2020 | DOI: 10.5380/re.v42i77.67434

*** Respectivamente: (1) Doutoranda pelo Cedeplar/UFMG |E-mail: tailinyventura@ hotmail.com | ORCID: 0000-0002-5657-798X | (2) Professor de Economia da Pontifícia Universidade Católica do Paraná (PUCPR) | E-mail: casonato.economia @ gmail.com | ORCID: 0000-0003-1280-3049
}

Esta publicação está licenciada sob os termos de

Creative Commons Atribuição-Não Comercial 4.0 Internacional 


\section{Introdução}

A metodologia dos programas de pesquisa científica de Imre Lakatos (MPPC) constituiu uma das reflexões mais importantes na filosofia da ciência (Martini, 2009). Lakatos considerou a ciência de forma geral como "um imenso programa de pesquisa, com a suprema regra heurística de Popper: arquitetar conjecturas que tenham maior conteúdo empírico que as predecessoras" (Lakatos, 1979, p. 162). Para Lakatos (1983, p. 144), sua metodologia propôs nova forma de construir a ciência.

$\mathrm{Na}$ perspectiva lakatosiana, as teorias não devem ser simplesmente descartadas na presença de reveses, já que as hipóteses que a circundam podem ser alteradas, mantendo a validade do "programa" em que estão inseridas (Lakatos, 1983, p. 145). Como será visto, um programa aos moldes de Lakatos deve seguir regras metodológicas constituídas em tradições científicas formadas por meio de um núcleo duro e hipóteses auxiliares que direcionam o caminho que esse programa deve seguir.

No escopo da economia, a epistemologia lakatosiana ganhou espaço particularmente a partir da década de 1980. Para Hands (1993, p. 69), a metodologia de Lakatos se tornou popular entre os economistas "porque ela oferece uma maneira de defender o que eles fazem", muitas vezes, revelando-se um método melhor do que outros. A partir de Latsis (1976, p. 3), é possível entender que a possibilidade de modificar hipóteses auxiliares, sem refutar toda a teoria, foi o motivo pelo qual a MPPC se tornou atraente na economia, impedindo que alguma teoria fosse descartada ante a presença de anomalias.

A MPPC passou a ser utilizada pelos metodólogos em economia, porém muitas críticas surgiram ao programa de Lakatos. Esse debate, entre críticos e apoiadores, mostrou-se dividido pela possibilidade de considerar as ideias lakatosinas úteis ao estudo da economia, já que alguns argumentam, como Hausman (1994), que elas não possuem muito a oferecer.

Este trabalho objetiva discutir a aplicação da abordagem de Lakatos à teoria econômica, e isso é realizado com base em três revisões: (i) primeiro discute-se a MPPC para o entendimento de quais são os critérios lakatosianos na delimitação de um programa de pesquisa; (ii) em seguida são analisadas algumas propostas de interpretação de Lakatos a abordagens econômicas, mostrando a possibilidade de estruturar cada uma dessas contribuições à luz da MPPC; (iii) por fím são 
verificadas algumas críticas às tentativas de utilizar as ideias lakatosianas na estruturação das teorias econômicas.

O restante do trabalho está dividido de maneira a refletir os passos descritos acima. A segunda seção apresenta a metodologia dos programas de pesquisa de Lakatos. A terceira seção revisa a literatura que julgou conveniente interpretar teorias econômicas sob a MPPC, enquanto a quarta seção mostra críticas à aplicação da proposta lakatosiana na ciência econômica. A quinta e última seção traz as considerações finais.

\title{
2. A metodologia dos programas de pesquisa (MPPC)
}

A epistemologia de Lakatos $(1979,1983)$ pressupôs que a unidade descritiva de feitos científicos não são as hipóteses que se apresentam de forma isolada, mas um programa de pesquisa (LAKATOS, 1883, p.144). ${ }^{1}$ Este consiste no conjunto de regras metodológicas que definem as direções dentro da pesquisa, desde as que devem ser evitadas àquelas a serem seguidas. Nas palavras do autor:

\begin{abstract}
A unidade básica de avaliação não deve ser uma teoria isolada ou uma conjunção de teorias, mas um « programa de pesquisa » com um « núcleo firme » convencionalmente aceito (e, portanto, "irrefutável" por decisão provisória) e com uma "heurística positiva" que define os problemas, esboça a construção de um conjunto de hipóteses auxiliares, prevê anomalias e as transforma de forma vitoriosa em exemplos de acordo com um plano pré-concebido (Lakatos, 1983, p. 144, tradução nossa, realce do autor).
\end{abstract}

Com base no desenvolvimento da metodologia dos programas de pesquisa científica, Lakatos afirmou que a história da ciência se expressa na história desses mesmos programas de pesquisa (Lakatos 1979, p. 162; Silveira, 1996, p. 220). A MPPC, dessa forma, é uma explicação para os desenvolvimentos científicos. De acordo com essa abordagem, as grandes realizações da ciência consistem em programas de pesquisa que podem ser avaliados em termos de transformações progressivas e regressivas de um determinado problema (Lakatos, 1983, p. 65).

\footnotetext{
${ }^{1}$ Sobre a epistemologia lakatosiana sugere-se a leitura dos originais em Lakatos $(1979,1989)$ e as interpretações de Silveira (1996) e Martini (2009).
} 
Nesse sentido, um programa de pesquisa representa um conjunto de teorias interligadas por heurísticas. ${ }^{2}$ Estas definem os caminhos da pesquisa por meio de um núcleo duro comum. ${ }^{3} \mathrm{O}$ núcleo duro expressa as hipóteses que não podem ser falseadas. ${ }^{4}$ Ele é definido e aceito pelos pesquisadores do programa, bem como protegido por um cinturão protetor.

A heurística de um programa pode ser negativa ou positiva (LAKATOS, 1983, p. 66). Uma heurística negativa define um conjunto de preposições que não podem ser modificadas, indicando caminhos que devem ser evitados, configurando, dessa forma, o conjunto de preposições irrefutáveis dentro do programa. Já a heurística positiva equivale ao conjunto de sugestões sobre como mudar e desenvolver as variantes que são refutáveis dentro do programa de pesquisa. Ou seja, a heurística positiva trata de caminhos que devem ser seguidos pelo programa, constituindo ideias sobre como desenvolvê-lo e como modificar seu cinto de proteção (Lakatos, 1979, p. 165).

Lakatos denominou de cinto protetor o conjunto de componentes substituíveis em um programa de pesquisa, que diferem da heurística negativa que contém os elementos não falseáveis mesmo na presença de contraexemplos (Lakatos, 1979, p. 163). Dessa forma, um programa de pesquisa contém ou gera componentes que poderiam ser abandonados ou substituídos sem se descartar a abordagem particular preconizada inicialmente como instrumento de explicação e previsão (Latsis, 1976).

O cinturão de proteção é caracterizado por hipóteses auxiliares desenvolvidas em torno do núcleo pelos próprios pesquisadores (Lakatos, 1979, p. 164; Silveira, 1996, p. 221). O cinto protetor é desenvolvido pelo choque dos componentes estruturais do programa de pesquisa (núcleo duro e heurística positiva) com suas principais anomalias (contraexemplos) atuais (Latsis, 1976). Com base nisso, Lakatos (1979, p. 163) afirmou que: “[é] esse cinto de proteção de hipóteses auxiliares que tem de suportar o impacto dos testes e ir se ajustando

\footnotetext{
${ }^{2}$ Em Lakatos (1979, p. 162) as heurísticas representam um conjunto de métodos que permitem a tanto a descoberta como a investigação científica.

3 “O núcleo duro é 'convencionalmente' aceito (e, portanto, 'irrefutável' por decisão provisória)". (Lakatos, 1983, p. 116, tradução nossa)

${ }^{4}$ A ideia de falseamento usada pelo autor versa sobre falseacionismo popperiano. Popper (2004) considerou que os experimentos para verificação devem ser feitos a partir de alguma teoria preconcebida. Dessa forma, uma teoria pode ser considerada válida não por meio de sua verificação (confirmação), mas sim pela possibilidade de sua refutação por meio do falseamento.
} 
e reajustando, ou mesmo ser completamente substituído, para defender o núcleo assim fortalecido".

Latsis (1976) considerou que um programa de pesquisa lakatosiano não é uma hipótese ou uma única teoria, ou mesmo uma série de hipóteses ou teorias. Antes, o autor lhe define como uma unidade orgânica que contém componentes rígidos e flexíveis - componentes estruturais, assim como aqueles não essenciais. Destes, dois são elementos fundamentais: (i) o "núcleo duro"; e (ii) a heurística positiva. Portanto, desistir deles significa abandonar o programa de pesquisa. $\mathrm{O}$ restante é entendido como flexível para a própria sobrevivência do programa.

$\mathrm{Na}$ perspectiva lakatosiana, o sucesso ou continuidade de um programa depende de sua capacidade de evoluir e incorporar fatos novos ao longo do tempo. Assim, a avaliação de programas de pesquisa ocorre através de regras que os consideram "progressivos" ou "regressivos".

Um programa será progressivo quando for capaz de explicar as anomalias de uma teoria anterior e prever novos fatos. Ou seja, quando as modificações no cinturão de proteção levam a novas predições dentro do programa. Nos termos de Lakatos (1983, p. 117, tradução nossa), um programa progressivo é aquele em que o "crescimento teórico antecipa seu crescimento empírico".

Por outro lado, um programa de pesquisa que apenas explica as novas evidências sem realizar novas previsões tem caráter regressivo, porque essas teorias foram "fabricadas" apenas para acomodar os fatos já conhecidos (Lakatos, 1983). Lakatos ilustra a questão citando o programa de pesquisa de Marx, considerando-o como regressivo por ter previsto fatos que não vieram a se concretizar (Lakatos, 1983, p.15). ${ }^{5}$

Os programas progressivos são preferíveis aos regressivos, porque quando um programa explica de forma progressiva os novos fatos, em relação a um programa "rival", esse último pode ser eliminado ou arquivado (LAKATOS, 1983). Além disso, a avaliação dos programas consiste em escolher quais deles serão considerados concorrentes. Logo, tais programas de pesquisa não existem de forma isolada (Backhouse, 1994) porque coexistem programas rivais.

Assim, a evolução da ciência ocorre quando um programa considerado como regressivo é abandonado em detrimento de um progressivo (Lakatos, 1983,

\footnotetext{
${ }^{5}$ A revolução socialista e o empobrecimento da classe trabalhadora foram previstos por Marx, no entanto não foram verificados (Lakatos, 1983). Esse exemplo também é encontrado em Silveira (1996).
} 
p. 144; Silveira, 1996, p. 225). A revolução científica se dá, nos termos do MPPC, quando os cientistas se alinham ao programa de pesquisa progressivo, que possui um excedente de conteúdo empírico que a outra teoria não possui. ${ }^{6}$ Porém isso é algo que ocorre ao longo do tempo em um processo demorado (Lakatos, 1983, p. 16, Silveira, 1996, p. 224). ${ }^{7}$

Ainda cabe ressaltar que na substituição de um programa de pesquisa por outro (ou de uma teoria por outra) não há obrigatoriedade de que o substituído tenha sido refutado. ${ }^{8}$ Assim, o caráter progressivo se verifica por excesso de conteúdo, e não por verificação de falsificação empírica ou teórica (Lakatos 1983, p. 147). Não existem testes ou experimentos que permitem eliminar um programa de pesquisa em detrimento de outro. ${ }^{9}$ Esse é um processo histórico que ocorre através do excesso de conteúdo que um programa apresenta com relação aos demais.

Em resumo, a MPPC de Lakatos argumenta que o progresso científico depende de programas de pesquisa rivais, que evoluem quando se mostram progressivos, ao se revelarem alternativas melhores por sua capacidade de prever fatos novos e conteúdo empírico (Lakatos, 1983, p. 146).

\section{A MPPC de Lakatos na ciência econômica}

A teoria lakatosiana ganhou maior espaço na ciência econômica durante a década de 1980 (Backhouse, 1994). Isso se verifica principalmente nos escritos sobre metodologia nessa área. Dessa nova discussão resultou um debate que dividiu aqueles que consideravam úteis ou não as ideias lakatosianas ao campo da economia (Hausman, 1994).

Muitos trabalhos aplicaram a MPPC a teorias econômicas (e.g. Blaug 1974; Latsis, 1972; 1976; Weintraub, 1985). Essas tentativas definiram os programas de pesquisa da economia aos moldes lakatosianos, ou seja, definiram um núcleo duro, hipóteses auxiliares e heurísticas. Na visão de Hands (1993), esse arcabouço é

\footnotetext{
${ }^{6}$ Ou seja, quando "um programa de pesquisa substitui (progressivamente ultrapassa) outro" (Lakatos, 1983, p. 144, tradução nossa).

7 "Podem passar décadas antes de os programas decolarem e se tornarem progressivos empiricamente" (Lakatos, 1983, p. 16, tradução nossa).

${ }^{8}$ A refutação a qual o autor se refere é aquele aos moldes do falseacionismo popperiano (Popper, 2004; Lakatos, 1983, p. 145).

${ }^{9}$ Nesse sentido, Lakatos (1983, p. 145) afirma que sua metodologia de investigação oferece critérios de avaliação para entender o progresso ou regresso de um programa de pesquisa.
} 
atraente aos economistas por ser mais flexível que o falseacionismo de Popper. ${ }^{10}$ Adicionalmente, para De Marchi (1991), tem a vantagem de permitir justificar as práticas econômicas. Nesse sentido, como coloca Hands (1993), os economistas estiveram utilizando as categorias de Lakatos para reconstruir parte de sua própria história científica. ${ }^{11}$

Backhouse (1994) afirma que o legado de Lakatos na metodologia econômica é significativo porque os economistas teriam achado "atraente" a ideia de avaliar programas de pesquisa, embora não estivessem pensando nos termos de Lakatos. Ainda mais por ter, em termos históricos, estimulado o interesse da economia no estudo da metodologia e fornecer direcionamentos de como a teoria pode se desenvolver a partir de uma metodologia científica.

Dessa forma, o restante da subseção está dividido para apresentar de maneira cronológica alguns trabalhos selecionados que usaram da MPPC na definição de programas de pesquisa na ciência econômica. ${ }^{12}$

\subsection{Latsis e a utilização da abordagem lakatosianana teoria da firma}

Latsis (1972) usa a definição de programas de pesquisa de Lakatos com o intuito de comparar duas versões para a teoria microeconômica da firma. A comparação é feita entre concorrência perfeita e monopólio, afirmando-se que ambas fazem parte do mesmo programa de pesquisa, uma vez que o núcleo duro, as heurísticas e hipóteses auxiliares, é o mesmo. Sendo assim, o programa em questão é considerado como programa "neoclássico" de pesquisa, rotulado como “determinismo situacional” (Latsis, 1972, p. 208). Princípios filosóficos como o

\footnotetext{
${ }^{10}$ Chalmers (1993) coloca que a obra de Lakatos realizou um refinamento da abordagem popperiana de falseamento. Nesse sentido Martini coloca que ele o fez incorporando elementos da obra de Kuhn. Mais sobre isso é encontrado em Kuhn (2000) e Martini (2009).

${ }^{11}$ Martini (2009) também dá tratamento especial ao trabalho de Hands e suas ideias acerca da aplicação do programa de Lakatos à economia.

${ }^{12}$ Esta proposta é semelhante àquela realizada por Martini (2009), que também revisou o uso da abordagem lakatosiana em economia. Porém, este autor deu tratamento especial à visão neoclássica, embora os trabalhos que ele utilizou como referência não estivessem restritos a essa corrente. Aqui, entretanto, algumas dessas mesmas referencias são revisitadas, mas na busca por considerar outras abordagens dentro da economia. Outra diferença com relação a Martini (2009) é que no seu trabalho são vistas as críticas a cada uma das aplicações de Lakatos, enquanto aqui pretende-se considerar apenas um contraponto mais geral à utilização da MPPC na economia, como se verá na quarta seção. Desta forma, a título de diferenciação, o presente trabalho argumentará que a coexistência de distintas visões econômicas para um mesmo objeto, que poderiam ser tomadas como programas de pesquisa na leitura de Lakatos, é uma dificuldade central para a aplicação da MPPC na ciência econômica.
} 
individualismo, escolhas racionais e agentes racionais são assumidos como intrínsecos a esse programa.

Considerando os conceitos de Lakatos, Latsis (1972) é um dos pioneiros na aplicação da MPPC em estudo de caso na ciência econômica. Ele definiu que o programa de pesquisa neoclássico se formava a partir de um núcleo duro com as seguintes hipóteses: maximização do lucro; informação perfeita; mercados perfeitos (ou em equilíbrio); e independência nas decisões. Tais características seriam os elementos irrefutáveis dentro do modelo.

Para o caso específico de concorrência perfeita, as hipóteses auxiliares seriam: a homogeneidade do produto; grande número de empresas; e livre movimentação (entrada e saída) do mercado. Em mercados monopolísticos, as heurísticas seriam praticamente idênticas as de concorrência perfeita, ainda que a estrutura de mercado lhe seja oposta (Latsis, 1972). A diferença entre as duas estruturas de mercado se manifesta na quantidade de empresas. ${ }^{13}$

Sobre as hipóteses que não devem ser aderidas pelo programa, estão aquelas sobre possibilidade de excesso de produção ou demanda, já que o modelo admite a hipótese de informação perfeita, resultando que o mercado sempre esteja em equilíbrio. Nesse sentido, fazem parte da heurística positiva do programa: a existência de equilíbrio; a construção de modelos estáticos; e, caso não exista um equilíbrio, ele deve ser alcançado por meio de ajustes (Latsis, 1972).

Entre outras coisas, Latsis (1972) também analisou se a teoria neoclássica regrediu ou progrediu. Apesar de ter argumentando que o desenvolvimento do modelo de competição monopolística foi considerado um dos maiores avanços na economia neoclássica, considerou esse um caso de regresso teórico (Latsis, 1972, p. 219, 234; Martini, 2009, p. 8). Essa conclusão deriva de sua análise ter se baseado no fato de o modelo de competição perfeita não ser verificado empiricamente. Assim, o programa ainda pode tentar acomodar algumas de suas anomalias, salvando o núcleo duro.

A extensão do modelo de competição perfeita para os demais tipos de estrutura de mercado poderia ser vista como um avanço teórico, no entanto os desdobramentos não significaram tal progresso para Latsis, que argumentou que

\footnotetext{
${ }^{13}$ De forma análoga, isso é extensível para os casos de oligopólios com a competição monopolística.
} 
eles acabam convergindo para as situações de competição perfeita ou monopólio (Latsis, 1972, p. 220).

Portanto, a conclusão de Latsis é que dentro do mesmo programa de pesquisa, o da teoria da firma, foram realizadas extensões falhas. Apesar disso, o ponto central desse autor é que, fazendo uma linha de desenvolvimento a partir da MPPC, tal programa regride porque não produz conteúdo empírico novo. Ou seja, o argumento de Latsis é de que os mercados em competição monopolística e oligopólios não são verificados, tal qual aqueles que se queria substituir. ${ }^{14}$

Em trabalho posterior, Latsis (1976) apresentou o mesmo programa de pesquisa, argumentando que a MPPC se apresenta de melhor forma do que qualquer outra metodologia de pesquisa na economia disponível até então para descrever e avaliar as teorias econômicas (Latsis, 1976, p. 2). A novidade trazida pela metodologia lakatosiana seria a possibilidade de analisar as transformações em determinados programas de pesquisa de forma dinâmica. Assim, em Latsis (1976, p. 15), a mudança ou a incorporação de certas hipóteses por outras constitui um critério de avaliação das teorias.

\subsection{Weintraub e a aplicação da abordagem lakatosiana à teoria do equilíbrio geral}

Weintraub (1985) analisou a teoria do equilíbrio geral partindo da abordagem lakatosiana, descrevendo-a em termos da MPPC. Nesse trabalho defendeu o uso do método de Lakatos por sua utilidade na construção de uma linha teórica a partir da qual seria possível verificar a existência de mudanças. Entretanto, Weintraub (1985, p. 25) afirmou ser necessário fazer ajustes na MPPC para que seja possível aplicá-la na análise do equilíbrio geral de Walras [1860].

O programa walrasiano foi definido por Weintraub (1985) a partir das seguintes preposições, consideradas constituintes do núcleo duro: existência de agentes econômicos; preferências dos agentes sobre os resultados econômicos; otimizam das escolhas pelos agentes; as escolhas são feitas a partir de mercados inter-relacionados; os resultados econômicos observados são coordenados e devem ser discutidos a partir de estados de equilíbrio.

\footnotetext{
${ }^{14}$ Sobre uma crítica ao argumento de Latsis, de que o programa de pesquisa neoclássico seria degenerativo, sugere-se o trabalho de Blaug (1975).
} 
Assim, Weintraub (1985) definiu como heurísticas positivas: a construção de teorias em que os agentes otimizem seus resultados, e que essas teorias fossem capazes de prever mudanças nos estados de equilíbrio. E como heurísticas negativas, aquilo que o programa não pode admitir: a irracionalidade humana, a não existência de equilíbrio e teorias que não testam seu núcleo duro. Nesse sentido, o programa neowalrasiano teria assumido a racionalidade humana e a existência de um equilíbrio, então tais princípios deveriam ser assumidos pelos pesquisadores ao trabalharem nesse programa.

Considerando que o núcleo duro de um programa de pesquisa não se consolida de uma única vez, Weintraub (1985) mostrou que as preposições atribuídas a tal programa neowalrasiano não nasceram com ele, mas foram se aglutinando a partir de diferentes propostas, citando como exemplo as contribuições de Mckenzie, Arrow, Debreu e Von Neumann. As proposições apresentadas como constituindo aquilo que se entende pelo programa de pesquisa do equilíbrio geral só foram consolidadas simultaneamente em 1950 (Weintraub, 1985, p. 28).

Quanto ao núcleo duro do modelo neowalrasiano, este dependeria da existência de um equilíbrio competitivo, e os trabalhos de Mckenzie e ArrowDebreu mostraram isso ao ir nessa direção, corroborando a manifestação de uma linha de pesquisa que garante consistência ao modelo, que mais tarde serviria como base para outros desdobramentos. ${ }^{15}$ Weintraub (1985) afirma que a reconstrução de uma série de artigos com o equilíbrio competitivo mostra a existência de um programa de pesquisa walrasiano no sentido lakatosiano.

Essa sequência de artigos exterioriza a consolidação do núcleo do programa de pesquisa, mostrando que o núcleo duro e as hipóteses básicas do modelo não existiram conjuntamente desde a época de Walras. A crítica de Weintraub à MPPC lakatosiana é que a existência de um núcleo duro não é tão rígida como apresentado originalmente nos trabalhos de Lakatos, já que, na medida em que o núcleo se consolida, as hipóteses sobre ele devem ser consideradas cada vez mais flexíveis (Weintraub, 1985, p. 36).

\footnotetext{
${ }^{15}$ Neste sentido, Weintraub (1985) cita os trabalhos de Hicks [1939] e Patinkin [1940], entre outros, buscando evidenciar a existência de uma continuidade deste programa de pesquisa.
} 


\subsection{Blaug e o emprego de Lakatos na história do pensamento econômico}

Blaug (1975) utilizou tanto a MPPC quanto a metodologia kuhnniana para revisar a História do Pensamento Econômico (HPE). Para o autor, as teorias foram desenvolvidas e consolidadas de maneira relacionada ao longo do tempo, e não individualmente em cada período. Isso implica que diferentes teorias estejam conectadas a uma rede de hipóteses, que configuram como ideias integradas entre elas. Com isso, Blaug (1975) sugeriu que esse mecanismo de ligação entre elas é passível de ser mais bem compreendido a partir das ideias lakatosianas.

Nesse sentido, seria possível reconstruir uma visão dentro da HPE, partindo do postulado smithiano de indivíduos maximizadores, passando pelas maximizações sujeitas às restrições, para, enfim, chegar-se à noção de um equilíbrio geral sistêmico entre mercados competitivos que se ajustam automaticamente. Justamente o que resultou em uma ferramenta disponível para a realizações de previsões na economia (Blaug, 1975, p. 161).

De acordo com Blaug (1975), o núcleo de pesquisa da Economia Política Clássica consistiu na racionalidade econômica e nos mercados competitivos, o que implicou admitir a informação perfeita, a substituibilidade dos fatores de produção e a independência na tomada das decisões individuais. Partindo disso, o autor definiu como "heurística positiva" desse programa: a divisão do mercado entre compradores e vendedores; a definição de estruturas de mercado; a condição ceteris paribus; as análises de primeira e segunda ordem; e outras.

Nesse sentido, a revolução marginalista ocorrida a partir de 1870 teria sido um movimento que, aderindo a esse núcleo duro da Economia Política Clássica, teria modificado sua heurística positiva e seu cinturão protetor, por ter incorporado a noção de utilidade marginal e focalizado as formas produtivas e seus custos (Blaug, 1975). ${ }^{16}$

Outro episódio pertinente considerado por Blaug (1975) foi o da Revolução Keynesiana, iniciado em 1936 com a publicação de "A Teoria geral do emprego, do juro e da moeda". Para Blaug (1975), esse avanço introduziu mudanças no núcleo duro da economia política vigente desde Smith, marcando o surgimento de um novo programa de pesquisa na economia. $\mathrm{O}$ autor destacou a inclusão de ideias

\footnotetext{
${ }^{16}$ É possível admitir que a atribuição da Revolução Marginalista como novo programa de pesquisa é tema controverso. Entretanto, de acordo com Blaug (1975), a partir desse episódio passaram a existir novos desdobramentos dos problemas enfrentados pelos teóricos, ao mesmo tempo que algumas ideias do período anterior foram descartadas por não encontrarem aderência na nova formulação teórica.
} 
como a propensão a consumir, a "lei psicológica fundamental" e a função consumo, que foram vistas por ele como hipóteses que não são seriam derivadas do comportamento maximizador do indivíduo. Antes, seriam oriundas da inferência positiva de Keynes a partir de sua análise do mundo.

Entretanto, segundo Blaug (1975), os pressupostos keynesianos de preferência por liquidez e eficiência marginal do capital derivaram do comportamento maximizador dos indivíduos. Conquanto tal aderência, e embora Blaug (1975) tenha assumido que Keynes admitiu algumas noções do programa de pesquisa que o antecedeu (como equilíbrio geral, estática comparativa e mercados em concorrência perfeita), os resultados de seu modelo teórico foram diferentes daqueles inferidos anteriormente, uma vez que foi assumida a possibilidade de crise e desemprego.

Além disso, para Blaug (1975), a teoria keynesiana, por meio do princípio da demanda efetiva, assumiu a possibilidade de superprodução, na contramão da Lei de Say, ao utilizar algo que foi negligenciado na revolução marginalista, os agregados econômicos. Ainda mais, a introdução do mercado monetário, considerando a economia como economias monetárias de produção, extinguiu a neutralidade da moeda e incorporou os ambientes de incerteza.

Dessa forma, as hipóteses keynesianas não promoveram apenas mudanças no cinturão protetor ou na heurística do programa, consistindo, para Blaug (1975) alterações no núcleo duro da economia vigente até então. Ele afirma:

O "núcleo duro" da teoria keynesiana, portanto, é realmente um novo "núcleo duro". O "cinturão protetor" da teoria keynesiana também se ergue a partir de novas hipóteses auxiliares: a função consumo, o multiplicador, o conceito de gastos autônomos e a demanda por moeda para especulação, contribuindo para a rigidez das taxas de juros de longo prazo (Blaug, 1975, p. 163, tradução nossa).

É dessa forma que Blaug (1975) considerou a Revolução Keynesiana como o surgimento de um novo programa de pesquisa na ciência econômica (Martini, 2009 , p. 10). Adicionalmente, apontou que o programa Keynesiano foi progressivo nos termos de Lakatos, uma vez que, além de explicar situações já conhecidas, também antecipou novos fatos (Blaug, 1975, p. 163).

Em Blaug (1975) também se discute a possibilidade de considerar a conversão dos economistas para o keynesianismo como o processo lakatosiano de migração de um programa degenerativo para um programa progressivo. No 
entanto, o autor fez ressalvas quanto à aderência dos postulados keynesianos, já que muitos economistas acreditaram que as políticas de cunho keynesiano deveriam ser adotadas, embora não confiassem nas bases com as quais essas políticas foram desenvolvidas. A partir disso, Blaug (1975) afirmou que a transição para a Revolução Keynesiana foi apenas parcial enquanto evolução lakatosiana de um programa degenerativo para outro progressivo.

Nessa mesma perspectiva, Blaug (1975) apontou que o Keynesianismo pôde ser visto como programa degenerativo sob o ponto de vista do pós-guerra, quando da perda do poder explicativo da teoria de Keynes para o desemprego crônico. A falta de evidências sobre alguns postulados, como o da propensão média a poupar, também fez com que o "programa" fosse revisto. Nesse contexto surgiram a Teoria do Ciclo de Vida de Modigliani e a Teoria da Renda Permanente de Friedman na década de 1950.

Blaug (1975) também destacou que foi nesse período que surgiram os modelos de crescimento econômico, convergindo para o equilíbrio com aquelas propostas pioneiras de Harrod [1939] e Domar [1946], fazendo com que os elementos principais do núcleo duro e do cinturão protetor do programa Keynesiano fossem abandonados (Blaug, 1975, p. 164).

Assim, Blaug (1975) argumentou que a metodologia lakatosiana é suficiente para explicar os fracassos e sucessos na história das teorias (ou dos programas de pesquisa). Nesse sentido, é possível considerar que o argumento dele se baseou no fato de a MPPC ser capaz de explicar o desenvolvimento de teorias, considerando-as progressivas ou regressivas, onde programas de pesquisa vão sendo substituídos ou reincorporados ao longo da história.

\subsection{Leijonhufvud e a revisão da Revolução Keynesiana em termos lakatosianos}

O trabalho de Leijonhufvud (1976) discutiu se a Revolução Keynesiana poderia ser vista a partir de uma interpretação em termos kuhnnianos, enquanto revolução científica, ou em termos lakatosianos, como mudança entre programas de pesquisa.

Para Leijonhufvud (1976), a história das teorias econômicas se mostrou, durante a maior parte do tempo, cronológica e progressiva, incorporando melhorias paulatinamente em termos de análises. Porém, tal narrativa histórica não estaria de 
acordo com alguma teoria científica, e não seria possível pressupor que a estrutura na qual a economia foi organizada pudesse ser definida de acordo com os postulados lakatosianos (Leijonhufvud, 1976, p. 68).

Leijonhufvud (1976) considerou a economia como área de pesquisa controversa, o que seria evidenciado pelos debates existentes tanto entre os programas de pesquisa como dentro deles. Nesse sentido, a MPPC poderia ser um caminho para iniciar a realização de distinções dentro economia e analisar diferentes programas de pesquisa (ou correntes de pensamento).

Segundo Leijonhufvud (1976), partindo-se da MPPC seria possível caracterizar determinadas propriedades de uma teoria econômica a partir do núcleo duro e do cinturão protetor. Por exemplo, quando dois modelos compartilham os mesmos pressupostos em seu núcleo duro, mas utilizam diferentes hipóteses no cinturão de proteção, seriam pertencentes ao mesmo programa de pesquisa.

Porém, Leijonhufvud (1976) fez a ressalva de que as definições das categorias em Lakatos não são suficientes para a definição de uma taxonomia que caracterize o que são ou não programas de pesquisa em economia. $\mathrm{O}$ autor ilustrou isso com base na Revolução Keynesiana, reconhecendo que seu corpo teórico caminhou na direção da produção de novos fatos, mas que, da mesma forma, inseriu-se na economia neoclássica de maneira progressiva.

\section{Críticas das aplicações da MPPC na economia}

Considerando que a história da ciência em Lakatos pode ser construída de forma racional, explicada pela hipótese de que os cientistas tomam decisões corretas referentes à metodologia da pesquisa, autores como Hausman (1992), Backhouse (1994), Hands (1993) e Hoover (1995) se posicionaram de maneira contrária à adoção do método lakatosiano na avaliação de hipóteses econômicas.

A MPPC de Lakatos recebeu críticas em toda a sua composição. Hausman (1992) afirmou que ela tem pouco a oferecer à ciência econômica, considerando que supor a necessidade de um núcleo duro se mostra controversa, porque deveria ser constituído de hipóteses rígidas que sejam, simultaneamente, irrefutáveis e imodificáveis.

Nesse sentido, os cientistas tenderam a discordar do que seria o núcleo duro de um mesmo programa de pesquisa. Por exemplo, Hausman (1992) afirmou que economistas não concordaram sobre o que consiste no núcleo duro do programa 
de pesquisa neoclássico. Controvérsias como essa fariam surgir, na opinião do autor, discussões inócuas, tornando frágil a aplicação da MPPC na economia. Isso fez com que Hausman (1992) considerasse de pouca utilidade a reconstrução de teorias econômicas sob a perspectiva lakatosiana.

Backhouse (1994) também considerou problemática a aplicação da MPPC de Lakatos na avaliação de progressão ou regressão dos programas de pesquisa em economia. Sua crítica retratou a possibilidade de que um mesmo programa possa passar por fases de progresso ou degeneração, como se em estivessem em desenvolvimento. Para ilustrar, Backhouse (1994, p. 177) mostrou as diferentes perspectivas que se teve da teoria keynesiana, enquanto um programa de pesquisa. Na década de 1940, tal visão poderia ser julgada progressiva, ao trazer contribuições e a previsão de novos fatos. Duas décadas depois, entretanto, não foi capaz de explicar sozinha os desdobramentos macroeconômicos, tornando necessária uma revisão teórica para sua recuperação.

Nesse sentido, é possível argumentar que a aplicação da MPPC não se mostrou necessariamente limitada na economia. Como no exemplo do impacto keynesiano, essa agenda de pesquisa se mostrou progressiva à sua época, embora possa ser caracterizada posteriormente como degenerativa ao concorrer com novas teses.

No entanto, o que se quer destacar é que a economia suporta uma série de propostas simultâneas das mais diversas correntes do pensamento econômico. E considerá-las a partir de diferentes "núcleos-duros" produz uma diversidade de programas de pesquisa concorrentes, sob o ponto de vista lakatosiano. Assim, como essas abordagens vão se desenvolvendo ao longo do tempo, sua pertinência como mais assertiva ou progressiva depende de sua adequabilidade para o problema econômico em questão, sem um teste definitivo do que e quando abandonar um programa de pesquisa.

Assim, a crítica mais severa quanto ao uso da MPPC de Lakatos se refere à estruturação que parte de um único núcleo duro que não possa ser modificado, e, por isso, a aplicação à economia pode resultar em muitos programas de pesquisa. Para Backhouse (1994), os programas de pesquisa deveriam ser caracterizados de maneira mais complexa, de modo a permitir sua mutabilidade futura. $\mathrm{E}$ isso mostrou a limitação existente na própria tentativa de conceituar aquilo que se quer considerar como um programa de pesquisa em economia. 
Hands (1993) afirmou que os economistas preferem a metodologia lakatosiana porque lhes permitiria uma defesa daquilo que já fazem em sua pesquisa. No entanto, a MPPC não ofereceu um guia de como aceitar ou rejeitas as teorias econômicas, e, dessa forma, a "MPPC de Lakatos pode constituir um progresso metodológico sobre o falseacionismo, mas ainda falha em fornecer aos economistas um critério aceitável para a escolha de teorias [...]" (Hands, 1993, p. 77).

Nesse aspecto, sobre a substituibilidade entre teorias a serem aceitas, o programa de pesquisa lakatosiano aplicado à economia deixa um espaço aberto. De forma radical, Hoover (1995) asseverou que a MPPC não se mostra útil para o estudo da economia. Para esse autor, o programa lakatosiano pecou por não ser capaz de explicar as relações entre diferentes teorias econômicas.

Em síntese, a controvérsia acerca da aplicação da MPPC ao estudo da economia se apresentou de forma crítica à inflexibilidade do núcleo de pesquisa e, da mesma forma, acerca da dificuldade em definir um núcleo duro dentro das teorias econômicas. É possível atribuir tal aspecto a particularidade da ciência econômica, em função da alta complexidade que se tem nas mais diferentes junções de hipóteses em seus mais diversos modelos. Principalmente a partir das distintas correntes de pensamento econômico que coexistem, todas trabalhando simultaneamente na falta de um critério definitivo para qualquer descarte teórico.

De acordo com Weiss (2002, p. 14), o uso da MPPC em economia é uma tarefa mais difícil porque Lakatos propôs sua metodologia inicialmente como um critério de avaliação para as ciências exatas, não para aquelas de caráter social. Em economia isso se reveste de importância porque, como argumentou Cavalieri (2007, p. 34), há a necessidade de se legitimar as diferentes visões de mundo dos economistas uma vez que existe uma peculiaridade inerente às ciências sociais: o pesquisador é objeto do seu próprio estudo.

Assim, pode-se complementar, o pesquisador em economia é investigador e investigado nos mais diversos problemas com que se depara, de modo que tanto a forma como surgem esses temas quanto a percepção acerca deles irão nortear o foco do trabalho do economista. Esse direcionamento revela-se tarefa mais fácil pela multiplicidade de ideias mantidas vivas no campo teórico da ciência econômica, pela pluralidade que resulta da coexistência de várias escolas do pensamento econômico, bem como pela possibilidade de resgate delas na HPE, como colocou Arida (1996, p. 42), na ideia de reinvenção da tradição. 


\subsection{A (in)aplicabilidade da epistemologia de Lakatos na economia}

Considerando os trabalhos discutidos ao longo deste artigo, é possível verificar a existência de diferentes abordagens teóricas levadas em consideração na aplicação da MPPC de Lakatos, e viu-se que cada uma das análises verificadas esteve associada ao contexto no qual tal avaliação foi desenvolvida.

Dessa forma, as teorias foram resgatadas de acordo com o problema econômico em questão, o que direcionou as hipóteses econômicas levadas em consideração, e, com isso, atribuindo à teoria o caráter de progressiva. Por exemplo, os argumentos iniciais utilizados pela visão neoclássica da economia se apoiaram na racionalidade econômica e na hipótese de pleno emprego, preocupados em discutir o funcionamento do mercado com uso racional de todos os recursos disponíveis. A teoria keynesiana, por outro lado, se fundamentou no princípio da demanda efetiva para mostrar como o mercado era capaz de funcionar normalmente, e de maneira racional, embora fosse incapaz de empregar sistematicamente todos os recursos econômicos.

Entende-se aqui, neste artigo, que a análise econômica possui caráter subjetivo, já que ela constitui uma leitura particular acerca do mundo que pode ser feita a partir de diferentes visões, de modo a não ser passível de testes empíricos definitivos para definir a melhor explicação tal qual aqueles das ciências exatas. A coexistência de distintas correntes de pensamento faz com que o princípio de programas degenerativos de Lakatos seja mais difícil de ser aplicado à ciência econômica.

\section{Considerações finais}

O trabalho apresentou a metodologia dos programas de pesquisa de Lakatos e, da mesma forma, a proposição que alguns autores fizeram de aplicá-la na economia. A partir das ideias de Lakatos, é possível dizer que um programa de pesquisa se apresenta como unidade integrada que se desenvolve em torno de um núcleo comum. Na perspectiva lakatosiana, uma teoria é refutada quando uma alternativa explica os fatos existentes e adiciona novo conteúdo empírico.

Na economia não há consenso sobre a utilização da MPPC. Os autores que a defenderam consideraram que ela permite que o cinturão de proteção e as heurísticas do programa sejam modificados, sem abandonar a teoria como um todo. Assim, quando se observa no mundo real fatos que vão contra às hipóteses 
auxiliares, elas podem ser modificadas sem que o programa de pesquisa seja abandonado. Porém, os autores que se mostram contrários à sua adoção mostram a dificuldade na definição do núcleo duro das teorias econômicas.

As diferenças entre programas de pesquisa se referem, em síntese, a diferenças em seu núcleo duro. Dessa forma parece não existir um programa capaz de extinguir tal questão dentro da ciência econômica. A economia enquanto uma ciência social substantiva, que busca explicar os sistemas econômicos, os quais mudam de acordo com transformações do mundo real, faz com que a MPPC se mostre limitada como método de pesquisa nessa ciência.

Nesse sentido, defende-se que a existência de diversas visões econômicas que poderiam ser caracterizadas como programas de pesquisa, a partir das distintas correntes de pensamento e visões de mundo, mostra-se uma dificuldade central para a utilização da MPPC na ciência econômica.

A complexidade desse campo e a dificuldade que os economistas possuem em concordar dificultam a construção de sua ciência em termos lakatosianos. Nesse sentido, o resultado é uma infinidade de “programas". É possível que a motivação de tal postura esteja em um caráter algo social da economia, que atribui a ela o caráter subjetivo, permitindo divergências entre seus pesquisadores quanto às diferentes formas de observar a realidade. Dessa forma, a ciência econômica acaba aceitando uma infinidade de programas e, da mesma forma, está propensa a maior pluralidade.

\section{Referências}

ARIDA, P. A história do pensamento econômico como teoria e retórica. In: REGO, J. M. (org.). Retórica na Economia. São Paulo: Editora 34, 1996.

BACKHOUSE, R. E. The Lakatosian legacy in economic methodology. In: BACKHOUSE, R. E. (ed.). New Directions in Economic Methodology. London: Routledge, 1994.

BLAUG, M. Kuhn versus Lakatos, or paradigms versus research programmes in the history of economics. History of Political Economy, v. 7, n. 4, p. 399-433, 1975.

CAV ALIERI, M. A. R. Como os economistas discordam: um ensaio metodológico sobre o "contexto da descoberta" em economia. Estudos Econômicos, v. 37, n. 2, p. 373-403, 2007. 
CHALMERS, A. F. O que é ciência afinal? São Paulo: Brasiliense, 1993.

DE MARCHI, N. Introduction: Rethinking Lakatos. In: DE MARCHI, N.; BLAUG, M. (ed.). Appraising economic theories: Studies in the Methodology of Research Programs. Aldershot: Edward Elgar, 1991.

FISHER, R. M. The logic of economic discovery: Neoclassical economics and the marginal revolution. Wheatsheaf Books, 1986.

HANDS, D. W. Popper and Lakatos in economic methodology. In: GUSTAFSSON, B.; KNUDSEN, C.; USLAKI, M. (ed.). Rationality, institutions and economic methodology. Routledge, 1993.

HAUSMAN, D. Kuhn, Lakatos and the character of economics. In: BACKHOUSE, R. E. (ed.). New Directions in Economic Methodology. London: Routledge, 1994.

HOOVER, K. D. Why does methodology matter for economics? The Economic Journal, v. 105, n. 430, p. 715-734, 1995.

KUHN, T. S. A estrutura das revoluções científicas. $3^{\text {a }}$ edição. São Paulo: Perspectiva, 2000.

LAKATOS, I. La metodología de los programas de investigación científica. Madrid: Alianza Editorial, 1983.

LAKATOS, I. O falseamento e a metodologia dos programas de pesquisa científica. In: LAKATOS, I; MUSGRAVE, A. (orgs.). A crítica $e$ o desenvolvimento do conhecimento. São Paulo: Editora Cultrix, p. 109-243, 1979.

LATSIS, S. J. A research programme in economics. In: LATSIS, S. J. Method and appraisal in economics. Cambridge: Cambridge University Press, p. 1-42, 1976.

LATSIS, S. J. Situational determinism in economics. The British Journal for the Philosophy of Science, v. 23, n. 3, p. 207-245, 1972.

LEIJONHUFVUD, A. Schools, 'revolutions', and research programmes in economic theory. In: LATSIS, S. J. Method and Appraisal in Economics. Cambridge: Cambridge University Press, 1976.

MARTINI, R. A. Os programas de pesquisa Lakatosianos e a metodologia da economia neoclássica: Contribuições e Críticas. In: VIII Congresso brasileiro de história econômica e IX Conferência internacional de história de empresas. Campinas, 2009.

POPPER, K. R. A lógica da pesquisa científica. Editora Cultrix, 2004. 
SILVEIRA, F. L. A metodologia dos programas de pesquisa: a epistemologia de Imre Lakatos. Caderno Catarinense de Ensino de Física, v. 13, n. 3, p. 219-230, 1996.

WEINTRAUB, E. R. Appraising general equilibrium analysis. Economics \& Philosophy, v. 1, n. 1, p. 23-37, 1985.

WEISS, M. The best way to do economics: moves and countermoves in the history of economic methodology. Durham: Duke University, 2002. (Working paper) 